\title{
Implications for the origins of pure anorthosites found in the feldspathic lunar meteorites, Dhofar 489 group
}

\author{
Hiroshi Nagaoka ${ }^{1,2^{*}}$, Hiroshi Takeda ${ }^{3}$, Yuzuru Karouji ${ }^{4}$, Makiko Ohtake $^{5}$, Akira Yamaguchi ${ }^{6,7}$, Shigekazu Yoneda ${ }^{8}$ \\ and Nobuyuki Hasebe $e^{1,2}$
}

\begin{abstract}
Remote observation by the reflectance spectrometers onboard the Japanese lunar explorer Kaguya (SELENE) showed the purest anorthosite (PAN) spots (>98\% plagioclase) at some large craters. Mineralogical and petrologic investigations on the feldspathic lunar meteorites, Dhofar 489 and Dhofar 911, revealed the presence of several pure anorthosite clasts. A comparison with Apollo nearside samples of ferroan anorthosite (FAN) indicated that of the FAN samples returned by the Apollo missions, sample 60015 is the largest anorthosite with the highest plagioclase abundance and homogeneous mafic mineral compositions. These pure anorthosites (>98\% plagioclase) have large chemical variations in $\mathrm{Mg}$ number $(\mathrm{Mg} \#=$ molar $100 \times \mathrm{Mg} /(\mathrm{Mg}+\mathrm{Fe}))$ of each coexisting mafic mineral. The variations imply that these pure anorthosites underwent complex formation processes and were not formed by simple flotation of plagioclase. The lunar highland samples with pure anorthosite and the PAN observed by Kaguya suggest that pure anorthosite is widely distributed as lunar crust lithology over the entire Moon.
\end{abstract}

Keywords: Moon; Lunar crust; Lunar magma ocean; Pure anorthosite; Lunar meteorite; Lunar returned sample; Mineralogy; Petrology

\section{Background}

On the basis of mineralogical and geochemical investigations of the returned Apollo lunar samples, we determined that ferroan anorthosite (FAN) is the main component of a lunar feldspathic crust (e.g., Taylor et al. 1991). In the global lunar magma ocean (LMO) model, the early lunar feldspathic crust was produced by the crystallization and flotation of plagioclase from the LMO (e.g., Warren 1985). However, the samples returned by Apollo missions were collected from a relatively small and geochemically restricted anomalous region of the central nearside of the Moon (Warren and Kallemeyn 1991). Our more recent knowledge and understanding of the lunar origin and evolution have also been expanded by an analysis of global remote sensing data

\footnotetext{
* Correspondence: hiroshi-nagaoka@asagi.waseda.jp

'Research Institute for Science and Engineering, Waseda University, Shinjuku, Tokyo 169-8555, Japan

${ }^{2}$ Schools of Advanced Science and Engineering, Waseda University, Shinjuku, Tokyo 169-8555, Japan

Full list of author information is available at the end of the article
}

(e.g., Binder 1998; Kato et al. 2010; Nozette et al. 1994). Compositional dichotomous distributions of $\mathrm{Mg}$ numbers $(\mathrm{Mg} \#=$ molar $100 \times \mathrm{Mg} /(\mathrm{Mg}+\mathrm{Fe}))$ in highlands determined by the spectral profiler (SP) on Kaguya (Ohtake et al. 2012) and Th abundances revealed by the gamma-ray spectrometer on Kaguya (Kobayashi et al. 2012) indicate that the central farside highland is more primitive because of the lowest $\mathrm{Th}$ abundances and highest Mg\#. The presence of rocks with high plagioclase abundances at some large craters, according to the Kaguya data, was reported by Ohtake et al. (2009), who proposed the lithology term purest anorthosite (PAN) for rocks with plagioclase content higher than $98 \%$.

A massive PAN layer could be a key for investigating the earliest anorthosite crystallized from the LMO and for providing a constraint on the modeling of the lunar feldspathic crust formation (Ohtake et al. 2009; Yamamoto et al. 2012). However, the presence of pure anorthosite rock samples has not been verified thus far in lunar feldspathic meteorites originating from randomly distributed nearsurface materials (Korotev et al. 2010). 
Our recent investigations of feldspathic lunar meteorites revealed that such pure anorthosite rock samples occur as common lithic clasts in feldspathic lunar meteorites Dhofar 489 and Dhofar 911 (Nagaoka et al. 2011, 2012; Takeda et al. 2006, 2012). Furthermore, Parmentier and Liang (2010) and Piskorz and Stevenson (2014) discussed the available formation mechanisms of pure anorthosite accumulation from LMO on the basis of each LMO model calculation. These model calculations indicated that pure anorthosite could have been formed from the LMO.

The lunar meteorite Dhofar 489, with a weight of $34.4 \mathrm{~g}$, is a feldspathic breccia including feldspathic lithology embedded in a much finer-grained and darker crystalline matrix (Takeda et al. 2006). An additional lunar meteorite Dhofar 911 was paired with Dhofar 489 on the basis of their cosmic-ray exposure (CRE) (Nishiizumi and Caffee 2006) and geochemical data (Korotev 2012). Although brief descriptions of petrography and reflectance spectroscopy of Dhofar 911 have been reported as a conference abstract (Takeda et al. 2012), detailed petrographic descriptions have not been reported thus far. Dhofar 489 exhibits some magnesian anorthosite clasts, including the magnesian anorthosite MA1 clast consisting of $95 \%$ plagioclase and $5 \%$ olivine $\left(\mathrm{Fo}_{78}\right)$. Such magnesian anorthosites are plotted on the gap between FAN and the Mg-suite on the An-Mg\# diagram (Takeda et al. 2006). Several large anorthosite clasts included in Dhofar 489 and Dhofar 911 are more abundant in plagioclase (>98\%) as compared with the previous magnesian anorthosites, which have plagioclase abundances as high as those of PAN (Ohtake et al. 2009). In this work, we confirm that the anorthosite clasts $(>1.5 \times 1.5 \mathrm{~mm})$ are pure anorthosites (PA), which are characterized on the basis of their mineralogical and petrologic data.

Some portions of Apollo FAN samples have been reported to consist of high abundances of plagioclase (>98\%; e.g., Dixon and Papike 1975; James et al. 1989, 1991; McGee 1993; Warren 1990). Moreover, some FAN samples are modally heterogeneous because they contain several lithologies (e.g., 60025 in Floss et al. 1998). The average proportion of plagioclase is approximately $96 \%$ for large FAN rocks (mass $>1 \mathrm{~g}$ ), although the massweighted average may be biased by Apollo FAN sample 60015 (Wieczorek et al. 2006). The Apollo FAN sample 60015 is the largest anorthosite, with nearly half the mass of the total FAN and the highest abundances of plagioclase (approximately 99\%) among FAN. Therefore, excluding 60015, the mass-weighted average proportion of plagioclase in FAN samples drops to 93\% (Wieczorek et al. 2006). We reinvestigate the mineralogy and petrology of 60015 and compare the results with those of pure anorthosites available from the Dhofar 489 group.
In this paper, we perform detailed mineralogical and petrologic studies of several pure anorthosite clasts in the Dhofar 489 group and Apollo FAN 60015 to elucidate the formation mechanism of the pure anorthosites. This paper also discusses a model of the origins of pure anorthosite on the basis of both the ground truth data and new remote sensing data.

\section{Methods}

Lunar meteorites Dhofar 489, Dhofar 911, and Apollo FAN 60015

A large 6.83-g chip of Dhofar 489 was obtained from the National Museum of Nature and Science (NMNS) (Takeda et al. 2006). As shown in Figure 1a, four samples were obtained from this chip. Sample a is classified in the present study; samples b, c, and d were classified to some extent in previous research, in which sample $d$ was subdivided into $\mathrm{d} 1$ and $\mathrm{d} 2$ (Takeda et al. 2006). Sample d2 is a subsplit of a white clast. The bulk chemical composition of this sample was previously determined by neutron-induced prompt gamma-ray analysis (PGA) and inductively coupled plasma mass spectrometry (ICP-MS; Karouji et al. 2004; Takeda et al. 2006), and its bulk composition implied that the $\mathrm{d} 2$ clast is a pristine anorthosite-rich sample (Takeda et al. 2006).

Because the mineralogy and petrology of $\mathrm{d} 2$ have not been investigated thus far, we describe the texture and mineral chemistry of the d2 in Dhofar 489 in more detail in this work. Sample a was further separated into three portions of a1, a2, and a3. Because sample a3 was adjoined to sample d, it contains part of the $\mathrm{d} 2$ clast. Three polished thin sections (PTSs), PTS a3-1, PTS a3-2, and PTS a3-3, were created from sample a3 (Figure 1a). A chip of Dhofar 911 provided by the Institute of Space and Astronautical Science (ISAS), Japan Aerospace Exploration Agency (JAXA), contains a large anorthosite clast (Takeda et al. 2012). In the present study, this chip was divided into two samples (sample $\mathrm{x}$ and sample y), the former of which containing the large anorthosite clast was used for PTS x-1 (Figure 1b).

The Apollo 16 returned sample, 60015, is a coarsegrained cataclastic anorthosite weighing $5.57 \mathrm{~kg}$ and is rather pure ( $>98 \%$ plagioclase) and pristine in bulk composition (e.g., Dixon and Papike 1975; McGee 1993; Sclar et al. 1973; Warren 1993). We investigated the mineralogy and petrology of 60015 by using a PTS of the sample, 129, provided by the National Aeronautics and Space Administration/Lyndon B. Johnson Space Center (NASA/JSC).

\section{Analytical methods}

We characterized the petrography of the PTSs by using a combination of petrographic microscopy, electron probe micro-analysis, and reflectance spectroscopy. 

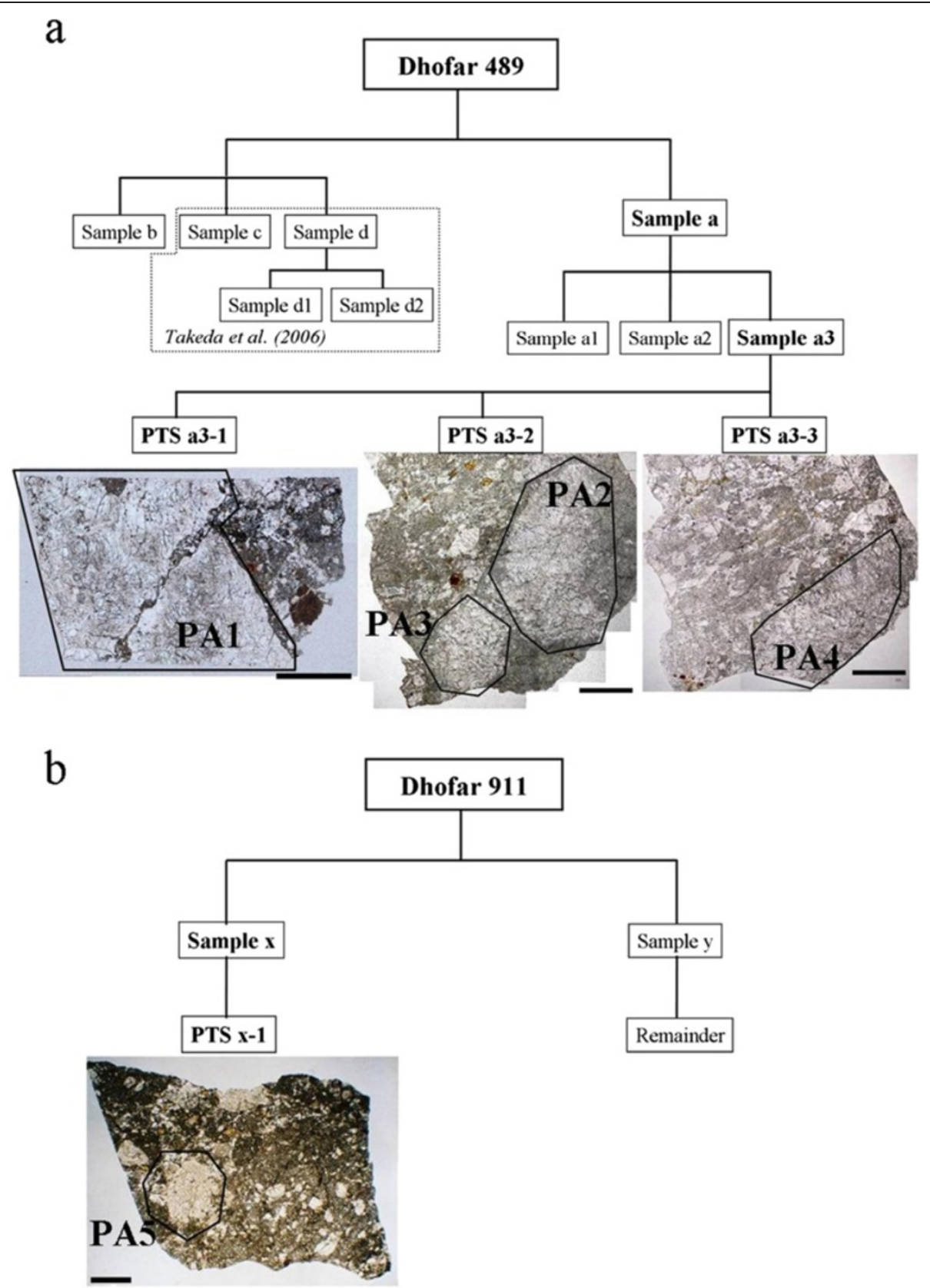

Figure 1 Sample separation procedures for (a) Dhofar $\mathbf{4 8 9}$ and (b) Dhofar 911. Polished thin section (PTS) a3-1, PTS a3-2, and PTS a3-3 were made from sample a3 of Dhofar 489. The Dhofar 489 slabs (sample $\mathrm{c}$ and sample d) were used by Takeda et al. (2006). Scale bar is $1 \mathrm{~mm}$ in size. In PTS a3-1, pure anorthosite 1 (PA1) is a part of the d2 clast (Takeda et al. 2006).

Before conducting the scanning electron microscope (SEM) and electron probe micro-analyzer (EPMA) analyses, the PTSs were coated by carbon. The elemental $\mathrm{X}$-ray maps and backscattered electron (BSE) images were collected by using the Hitachi S-3000 N SEM (Hitachi Ltd., Chiyoda-ku, Japan) at Waseda University. Quantitative mineral compositions were analyzed with the JEOL JXA-8900 EPMA (JEOL Ltd., Akishima-shi, Japan) at the Atmosphere and Ocean Research Institute
(AORI), University of Tokyo, with a well-characterized oxide and silicate standards at $15 \mathrm{kV}, 1.2 \times 10^{-8} \mathrm{~A}$, and an electron beam with a diameter of approximately $5 \mu \mathrm{m}$ (e.g., Nagaoka et al. 2013; Takeda et al. 2006).

The ultraviolet-visible-near infrared (UV-VIS-NIR) bidirectional reflectance spectrum of the $\mathrm{d} 2$ clast was measured by a JASCO reflectance spectrometer (JASCO, Hachioji-shi, Japan) at JAXA. A chip sample of the d2 clast used for reflectance measurement was prepared 
from the cut surface of sample a3 after making PTS a31. The spectrometer incidence angle was $30^{\circ}$, and the emission angle was $0^{\circ}$.

\section{Results}

Mineral chemistry and petrography of Dhofar 489

Dhofar 489 is a feldspathic breccia consisting of mineral fragments and lithic and glassy clasts embedded in a much finer-grained dark crystalline matrix (Figure 1a). PTS a3-1 $(4.3 \times 2.5 \mathrm{~mm})$ contains one large anorthosite clast $(\mathrm{d} 2)$ in the crystalline matrix with fragments of plagioclase and angular olivine up to 0.5 and $0.1 \mathrm{~mm}$ across, respectively. The $\mathrm{d} 2$ clast is classified as pure anorthosite 1 (PA1). PTS a3-2 $(5.3 \times 4.9 \mathrm{~mm})$ contains two large anorthosite clasts classified as PA2 and PA3 in the crystalline matrix with fragments of plagioclase and angular olivine up to 0.7 and $0.3 \mathrm{~mm}$ across, respectively. PTS a3-3 $(5.1 \times 4.5 \mathrm{~mm})$ contains one large anorthosite clast classified as PA4 in the crystalline matrix with fragments of plagioclase and angular olivine up to 0.9 and $0.2 \mathrm{~mm}$ across, respectively. The descriptions of the Dhofar 489 breccia matrix have been reported in detail by Takeda et al. (2006).
The crystalline matrix in Dhofar 489 shows a magnesian anorthositic composition (31 wt.\% average $\mathrm{Al}_{2} \mathrm{O}_{3}$, average $\mathrm{Mg \#} \mathrm{79).} \mathrm{The} \mathrm{An} \mathrm{values} \mathrm{of} \mathrm{the} \mathrm{plagioclase} \mathrm{frag-}$ ments are uniform $\left(\mathrm{An}_{96-97}\right)$. The Fo contents of the olivine fragments range from $\mathrm{Fo}_{73}$ to $\mathrm{Fo}_{88}$. These analytical data of Dhofar 489 determined by this work are within the range of those reported previously $\left(\mathrm{Fo}_{71-87}\right.$, $\mathrm{An}_{\text {93-99; }}$ Takeda et al. 2006).

\section{Pure anorthosite}

In this section, we describe the petrography of the pure anorthosite clasts (PA1, PA2, PA3, and PA4) embedded in Dhofar 489 (Figure 1a). Their sizes are larger than $1.5 \times 1.5 \mathrm{~mm}$; photomicrographs of these clasts are presented in Figures 2 and 3. Although these anorthosite clasts are classified as 'anorthosite' on the basis of classification of plutonic lunar highland rocks (Prinz and Keil 1977), the term 'PA' is used in the present study according to their very high abundances of plagioclase (>98\%).

Clast PA1: PA1 $(3.6 \times 2.5 \mathrm{~mm})$ is a silky white clast (Figure 1a) composed of $>99$ area\% plagioclase $\left(\mathrm{An}_{95-96}\right)$ and traces of olivine $\left(\mathrm{Fo}_{61-63}\right)$, orthopyroxene $\left(\mathrm{Wo}_{6} \mathrm{En}_{57} \mathrm{Fs}_{37}\right.$ $\mathrm{Wo}_{3} \mathrm{En}_{65} \mathrm{Fs}_{32} ; \mathrm{Mg} \# 60$ to 66 ), and troilite (Figures $2 \mathrm{a}$ and 4a). Smaller mafic minerals including orthopyroxene and

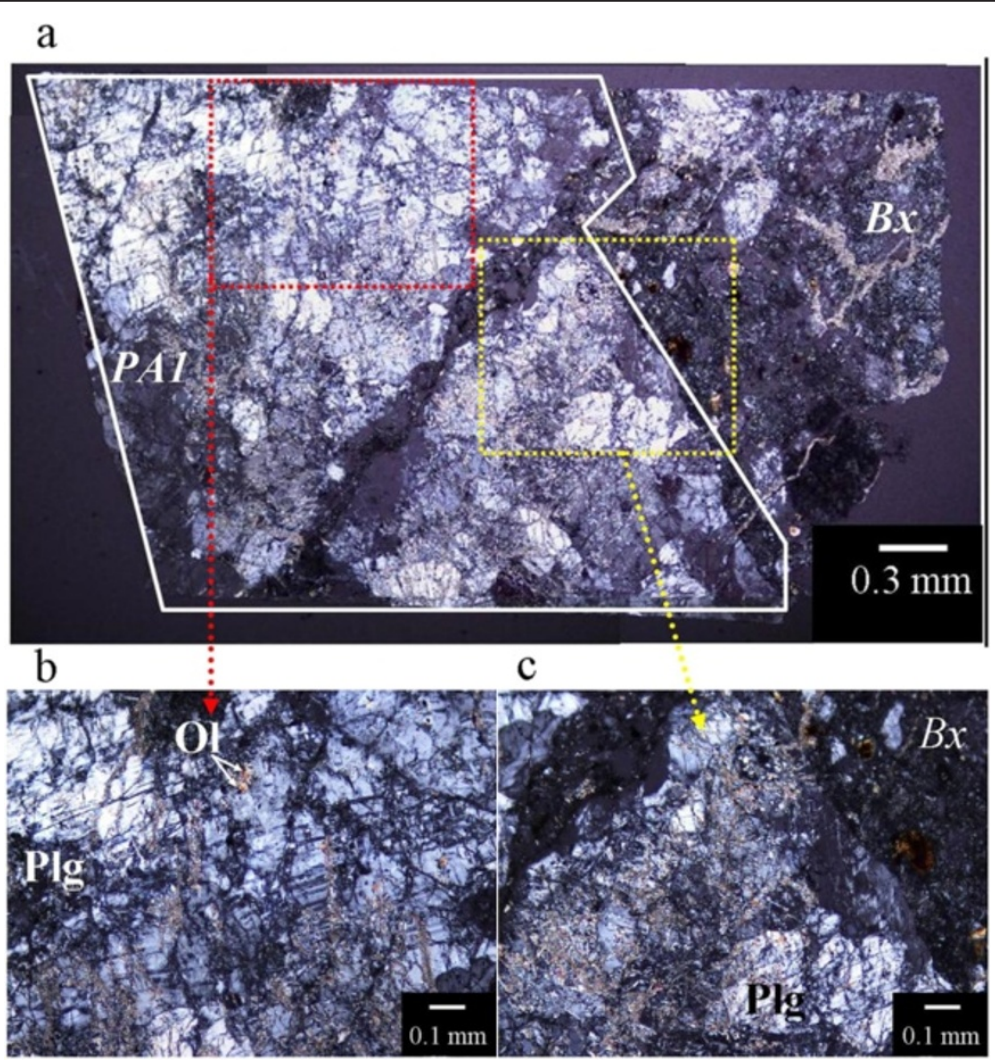

Figure 2 Photomicrographs (cross-polarized view) of pure anorthosite clast (PA1). (a) The entire clast of PA1. (b) The detailed textures of plagioclase (Plg) and olivine (OI) surrounded by a red dotted line in (a). (c) The detailed texture of Plg surrounded by a yellow dotted line in (a). The textures are disturbed by networks of weathered products. Bx, breccia matrix. 


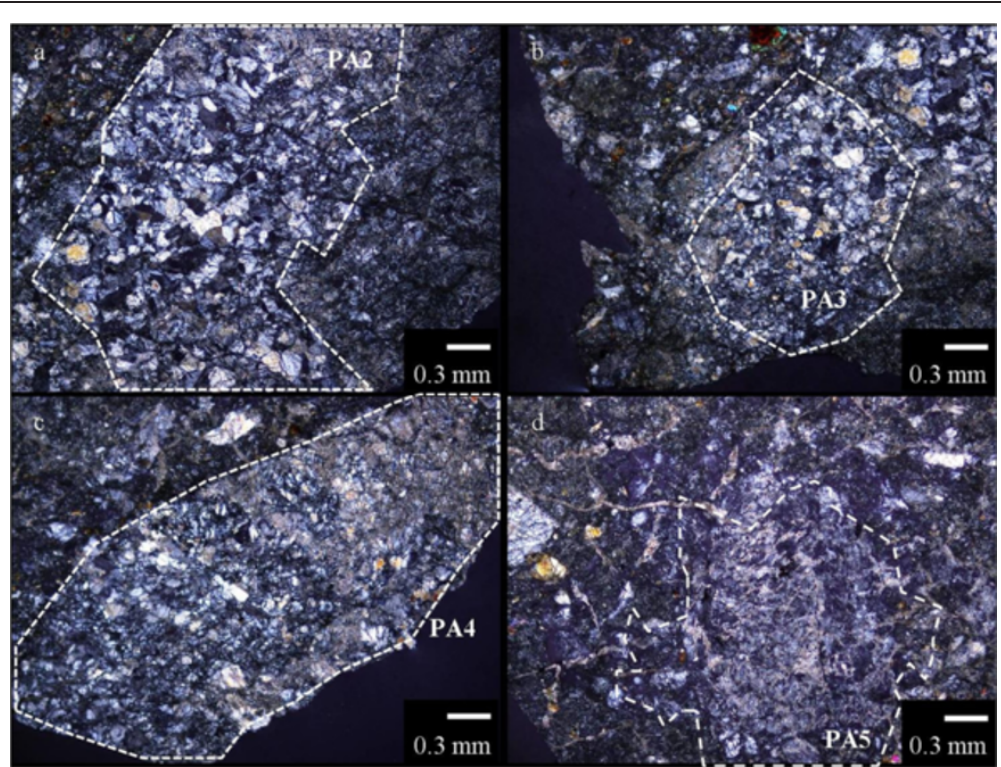

Figure 3 Photomicrographs (cross-polarized view) of pure anorthosite clasts. (a) PA2, (b) PA3, (c) PA4, and (d) PA5. Scale bar is $0.3 \mathrm{~mm}$ in size.

olivine < approximately $0.05 \mathrm{~mm}$ with angular shapes exist in the grain boundaries between euhedral and subhedral crystalline plagioclase. The grain sizes of plagioclase crystals are coarse, up to approximately $2 \mathrm{~mm}$, with twin lamellae of the large plagioclase grain (Figure 2b). Although the textures are disturbed by networks of carbonates due to terrestrial weathering (Figure 2c), we can recognize the original igneous textures with albite twinning textures within each original crystal (Figure 2b,c). The presence of the coarse twinned plagioclase grains $(>1 \mathrm{~mm}$ across) enclosing the small mafic minerals indicates that this clast may be part of a coarse-grained igneous anorthosite. The average mineral compositions of PA1 are summarized in Table 1.

Clast PA2: PA2 is a silky white clast (Figure 1a) composed of varying sizes $<0.5 \mathrm{~mm}$ of angular plagioclase crystals that are apparently finer than those of PA1 (Figure 3a). PA2 $(1.9 \times 3.4 \mathrm{~mm})$ is composed of nearly 100 area\% plagioclase $\left(\mathrm{An}_{94-97}\right)$ and traces of low-Ca pyroxene $\left(\mathrm{Wo}_{10} \mathrm{En}_{66} \mathrm{Fs}_{24} ; \mathrm{Mg} \# 71\right.$ to 72$)$ and troilite (Figure 4b). PA2 may be part of an anorthosite

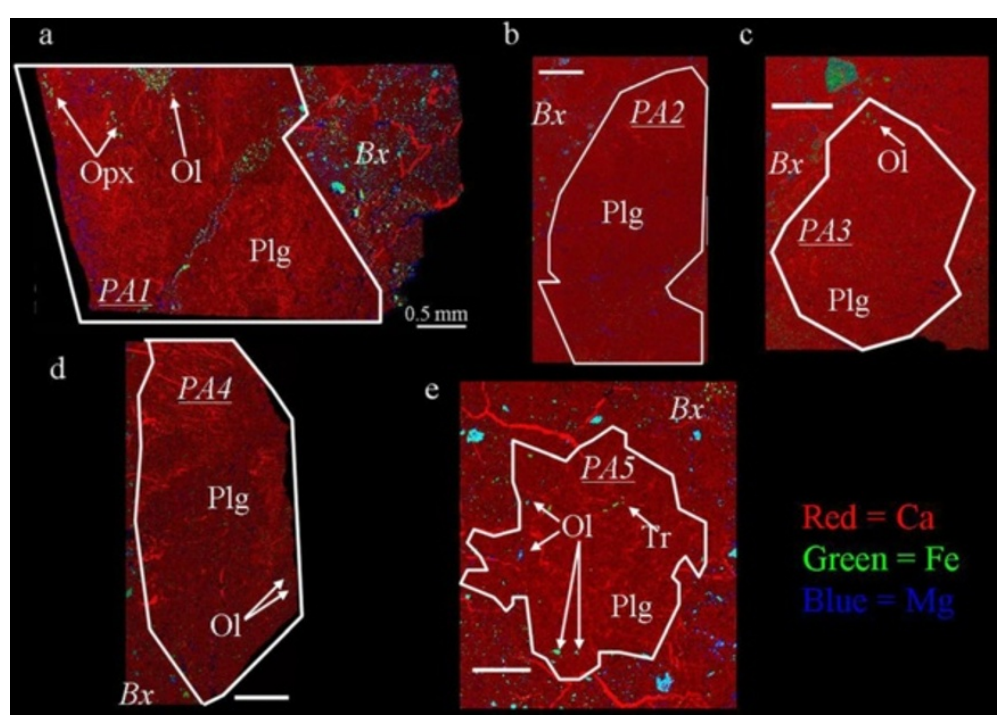

Figure 4 Combined X-ray elemental maps of five pure anorthosite clasts. (a) PA1 in Dhofar 489 polished thin section (PTS) a3-1. (b) PA2 in Dhofar 489 PTS a3-2. (c) PA3 in Dhofar 489 PTS a3-2. (d) PA4 in Dhofar 489 PTS a3-3. (e) PA5 in Dhofar 911 PTS x-1. Red represents Ca, green represents $\mathrm{Fe}$, and blue represents Mg. Scale bar is $0.5 \mathrm{~mm}$ in size. Plg, plagioclase; Ol, olivine; Opx, orthopyroxene; Tr, troilite; and Bx, breccia matrix. 
Table 1 Average mineral compositions (wt.\%) in the PA1 and PA5 clasts

\begin{tabular}{|c|c|c|c|c|c|c|c|c|c|c|}
\hline \multirow[t]{4}{*}{ Oxide } & \multicolumn{6}{|c|}{ Minerals in the PA1 clast } & \multicolumn{4}{|c|}{ Minerals in the PA5 clast } \\
\hline & \multirow{2}{*}{\multicolumn{2}{|c|}{$\begin{array}{l}\text { Plagioclase } \\
\text { No. }=6\end{array}$}} & \multirow{2}{*}{\multicolumn{2}{|c|}{$\begin{array}{l}\text { Olivine } \\
\text { No. }=2\end{array}$}} & \multirow{2}{*}{\multicolumn{2}{|c|}{$\begin{array}{l}\text { Orthopyroxene } \\
\text { No. }=3\end{array}$}} & \multirow{2}{*}{\multicolumn{2}{|c|}{$\begin{array}{l}\text { Plagioclase } \\
\text { No. }=5\end{array}$}} & \multirow{2}{*}{\multicolumn{2}{|c|}{$\begin{array}{l}\text { Olivine } \\
\text { No. }=7\end{array}$}} \\
\hline & & & & & & & & & & \\
\hline & Con. & SD & Con. & SD & Con. & SD & Con. & SD & Con. & SD \\
\hline $\mathrm{SiO}_{2}$ & 43.89 & 0.51 & 36.72 & 0.39 & 50.02 & 0.92 & 44.85 & 0.17 & 38.20 & 1.14 \\
\hline $\mathrm{TiO}_{2}$ & b.d. & & 0.14 & 0.04 & 0.84 & 0.24 & b.d. & & b.d. & \\
\hline $\mathrm{Al}_{2} \mathrm{O}_{3}$ & 34.65 & 0.27 & 0.61 & 0.02 & 1.76 & 0.35 & 35.13 & 0.15 & 0.67 & 0.62 \\
\hline $\mathrm{Cr}_{2} \mathrm{O}_{3}$ & b.d. & & 0.06 & 0.00 & 0.34 & 0.04 & b.d. & & 0.06 & 0.02 \\
\hline $\mathrm{FeO}$ & 0.17 & 0.03 & 31.10 & 0.65 & 21.69 & 1.48 & 0.16 & 0.02 & 18.89 & 3.11 \\
\hline $\mathrm{MnO}$ & 0.05 & 0.02 & 0.47 & 0.07 & 0.47 & 0.02 & b.d. & & 0.21 & 0.05 \\
\hline $\mathrm{MgO}$ & 0.15 & 0.03 & 28.20 & 0.89 & 21.47 & 2.65 & 0.21 & 0.04 & 40.31 & 3.12 \\
\hline $\mathrm{CaO}$ & 19.14 & 0.24 & 0.69 & 0.09 & 2.30 & 0.65 & 19.05 & 0.08 & 0.29 & 0.21 \\
\hline $\mathrm{Na}_{2} \mathrm{O}$ & 0.46 & 0.04 & 0.04 & 0.01 & 0.07 & 0.02 & 0.49 & 0.03 & 0.10 & 0.05 \\
\hline $\mathrm{K}_{2} \mathrm{O}$ & b.d. & & b.d. & & b.d. & & 0.02 & 0.00 & b.d. & \\
\hline $\mathrm{P}_{2} \mathrm{O}_{5}$ & 0.15 & 0.01 & b.d. & & b.d. & & 0.17 & 0.00 & b.d. & \\
\hline $\mathrm{V}_{2} \mathrm{O}_{3}$ & b.d. & & b.d. & & 0.05 & 0.01 & b.d. & & b.d. & \\
\hline Total & 98.66 & & 98.03 & & 99.01 & & 100.08 & & 98.73 & \\
\hline Mg\# & 63 & & 61.8 & & 63.8 & & 70 & & 79.1 & \\
\hline An & 95.8 & & - & & - & & 95.5 & & - & \\
\hline$A b$ & 4.2 & & - & & - & & 4.4 & & - & \\
\hline Or & - & & - & & - & & 0.1 & & - & \\
\hline \multicolumn{11}{|l|}{ Cation } \\
\hline $\mathrm{Ca}$ & 2.883 & & 0.122 & & 0.382 & & 2.823 & & 0.048 & \\
\hline $\mathrm{Mg}$ & 0.034 & & 7.007 & & 4.836 & & 0.044 & & 9.356 & \\
\hline $\mathrm{Fe}$ & 0.020 & & 4.335 & & 2.747 & & 0.019 & & 2.472 & \\
\hline
\end{tabular}

b.d., below detection limit; No., number of analyzed grains; Con., concentration; SD, standard deviation indicates standard deviation variation (1 $\sigma$ ) of the individual mineral compositions and reflects the compositional variation of each mineral in each clast.

consisting of finer-grained plagioclase than that in PA1. The Mg\# of mafic minerals are homogeneous (Mg\# 71 to 72 ).

Clast PA3: PA3 is a silky white clast consisting of finegrained plagioclase (Figures $1 \mathrm{a}$ and $3 \mathrm{~b}$ ). The angular plagioclase crystals are also finer than those in PA1 (Figure $3 \mathrm{~b}$ ), and their grain sizes are mostly $<0.3 \mathrm{~mm}$. The PA3 clast $(1.7 \times 1.7 \mathrm{~mm})$ is a fine-grained anorthosite of $>99$ area\% plagioclase $\left(\mathrm{An}_{95-97}\right)$ and traces of olivine, low-Ca pyroxene, and augite (Figure 4c). Ferroan olivine $\left(\mathrm{Fo}_{57}\right)$ and augite $\left(\mathrm{Wo}_{34} \mathrm{En}_{20} \mathrm{Fs}_{46} ; \mathrm{Mg \#} 29\right)$ are detected in the upper portion of this clast, and minor magnesian low-Ca pyroxene $\left(\mathrm{Wo}_{12} \mathrm{En}_{62} \mathrm{Fs}_{26}\right.$ to $\mathrm{Wo}_{12} \mathrm{En}_{63} \mathrm{Fs}_{25}$; $\mathrm{Mg} \# 69$ to 71$)$ and augite $\left(\mathrm{Wo}_{33} \mathrm{En}_{49} \mathrm{Fs}_{18} ; \mathrm{Mg \#} 72\right)$ are present in the center. The Mg\# of the mafic minerals are heterogeneous (Mg\# 30 to 70 ).

Clast PA4: PA4 is a silky white clast (Figure 1a) composed of highly shocked anorthosite (Figure 3c). The PA4 clast $(1.7 \times 3.9 \mathrm{~mm})$ is a fine-grained anorthosite composed of $>99$ area\% plagioclase $\left(\mathrm{An}_{94-96}\right)$ and traces of olivine $\left(\mathrm{Fo}_{64-68}\right)$, low-Ca pyroxene $\left(\mathrm{Wo}_{11} \mathrm{En}_{63} \mathrm{Fs}_{26}\right.$;
Mg\# 70), and troilite (Figure 4d). The Mg\# of mafic minerals are homogeneous (Mg\# 64 to 70).

These four clasts are composed of $>98$ area $\%$ plagioclase and small amounts of mafic minerals $(<0.1 \mathrm{~mm})$. Although the texture of PA1 preserves coarse plagioclase ( $>1 \mathrm{~mm}$ ), other clasts show finer-grained textures. The anorthosite clast AN1 in Dhofar 489 reported by Takeda et al. (2006) is classified as a pure anorthosite according to our criteria. The Fo content of olivine in AN1 $\left(\mathrm{Fo}_{78}\right)$ is significantly higher than the ferroan olivines in PA1 $\left(\mathrm{Fo}_{61-63}\right)$, PA3 $\left(\mathrm{Fo}_{57}\right)$, and PA4 $\left(\mathrm{Fo}_{64-68}\right)$.

\section{Mineral chemistry and petrography of Dhofar 911}

Dhofar 911 is a feldspathic breccia consisting of mineral fragments and lithic clasts in a dark fine-grained crystalline matrix, similar to that of Dhofar 489 (Takeda et al. 2006). PTS $x-1(7.6 \times 5.4 \mathrm{~mm})$ contains two large clasts in the crystalline matrix (Figure 1b). The first is classified as pure anorthosite 5 (PA5), and the second is a magnesian anorthosite with a granulitic breccia texture. Such clasts as spinel troctolite with the $\mathrm{Mg}-\mathrm{Al}$ spinel in 
Dhofar 489 and magnesian troctolitic granulite in the Dhofar 489 group (Takeda et al. 2006, 2007, 2008; Treiman et al. 2010) are not detected in PTS x-1. Plagioclase fragments up to $0.9 \mathrm{~mm}$ across and large angular fragments of orange-yellow olivine crystals with a maximum size of $0.4 \times 0.2 \mathrm{~mm}$ are present in the crystalline matrix. The large orange-yellow olivines are common in the matrix of other rocks of the Dhofar 489 group (Takeda et al. 2006, 2007, 2008).

The crystalline matrix in Dhofar 911 has a magnesian anorthositic composition (30 wt.\% average $\mathrm{Al}_{2} \mathrm{O}_{3}$, average Mg\# 78) similar to that in Dhofar 489. The An values of plagioclase fragments in Dhofar 911 PTS $x-1$ range from $\mathrm{An}_{96}$ to $\mathrm{An}_{97}$, and the Fo contents of olivine fragments range from $\mathrm{Fo}_{73}$ to $\mathrm{Fo}_{86}$. The largest angular olivine fragment composition is $\mathrm{Fo}_{76}$. Both compositional ranges of $\mathrm{An}_{96-97}$ in plagioclase fragments and $\mathrm{Fo}_{73-86}$ in olivine fragments in Dhofar 911 PTS x-1 are in the range of those in Dhofar $489\left(\mathrm{An}_{96-97} ; \mathrm{Fo}_{73-88}\right)$. Similar compositions of the crystalline matrix and mineral fragments could support the pairing of Dhofar 489 and Dhofar 911 (Nishiizumi and Caffee 2006).

\section{Pure anorthosite}

Clast PA5: PA5 $(1.9 \times 1.9 \mathrm{~mm})$ is a silky white clast (Figure 1b) composed of 98.6 area\% plagioclase ( $\left.\mathrm{An}_{95-96}\right)$, 1.0 area\% olivine $\left(\mathrm{Fo}_{75-85}\right)$, and traces of troilite (Figures $3 \mathrm{~d}$ and 4e). The largest plagioclase crystal is coarse up to $1.8 \mathrm{~mm}$. The shock textures by meteor impact are disturbed by networks of weathering products (Figure $3 \mathrm{~d}$ ). Some small olivine crystals $(<0.1 \mathrm{~mm})$ are located at the marginal part of the largest crystalline plagioclase grains, which partly retain albite twinning. The coarse twinned plagioclase grains indicate an igneous origin, similar to that of PA1. The average mineral compositions are presented in Table 1.

\section{Magnesian anorthosite with granulitic breccia texture}

One large anorthosite clast $(2.4 \times 1.0 \mathrm{~mm})$ is contained in Dhofar 911 PTS $\mathrm{x}-1$. This clast is composed of 96 area\% plagioclase $\left(\mathrm{An}_{96}\right), 3$ area\% olivine, and traces of troilite (Figure 5a,b). The primary textures of plagioclase grains cannot be observed due to shock damages. An aggregate of amoeboid olivines $\left(\mathrm{Fo}_{85}\right)$ of $0.15 \times 0.46 \mathrm{~mm}$ with rounded shapes is located at the left edge of this clast (Figure $5 \mathrm{a}, \mathrm{b})$, and small ferroan olivine $\left(\mathrm{Fo}_{53}\right)$ is found at the center.

The sizes of olivines at the left edge of this clast are larger than those in the pure anorthosites $(<0.1 \mathrm{~mm}$ across; PA1 to PA5). The amoeboid aggregate of olivines with rounded shapes suggests that this clast may be a coarse-grained granulitic breccia. The textures of granulitic olivines and the mineral mode in this clast are very close to the description of the magnesian anorthosite

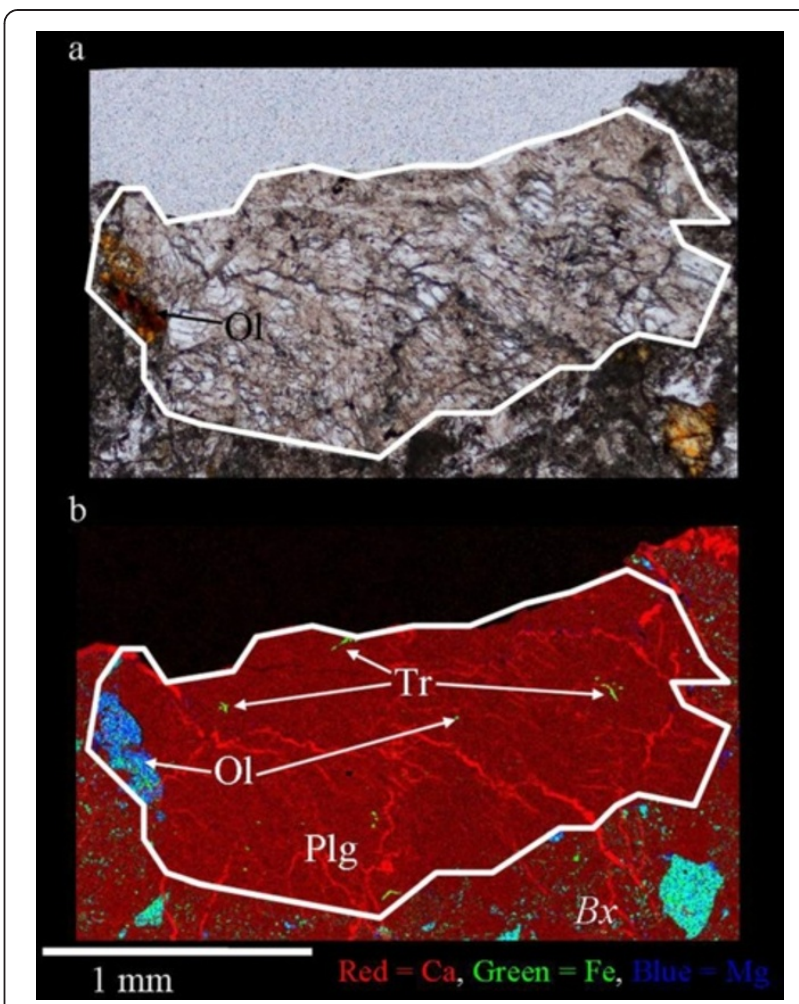

Figure 5 Images of the magnesian anorthosite with granulitic breccia texture in Dhofar 911 polished thin section (PTS) x-1. (a) Photomicrograph of magnesian anorthosite with granulitic breccia texture in Dhofar 911 PTS x-1. (b) Combined X-ray elemental maps of magnesian anorthosite with granulitic breccia texture in Dhofar 911 PTS x-1. Red represents Ca, green represents Fe, and blue represents Mg. Plg, plagioclase; OI, olivine; Tr, troilite; and Bx, breccia matrix.

(MA1) in Dhofar 489 (Takeda et al. 2006). The mineral compositions of granulitic olivines $\left(\mathrm{Fo}_{85}\right)$ are slightly more magnesian than those in MA1 $\left(\mathrm{Fo}_{79}\right)$ are.

\section{Reflectance-spectroscopic results of pure anorthosite}

The reflectance spectrum of PA1 in Dhofar 489 (Figure 6) was compared with the spectra of Dhofar 911 PA5 and the breccia matrix $(\mathrm{Bx})$ reported by Takeda et al. (2012). The spectrum of PA1 shows absorption at approximately 1,000 and 1,250 to $1,300 \mathrm{~nm}$. The latter absorption can be attributed to the presence of plagioclase. The slope at approximately $1,000 \mathrm{~nm}$ could have been affected by olivine and pyroxene mineral fragments embedded in the $\mathrm{Bx}$ near PA1 or melt veins crossing PA1. The strongest absorption at approximately 1,250 to $1,300 \mathrm{~nm}$ bands can be attributed to plagioclase, as was confirmed in the spectrum of PA5. This result is consistent with our mineralogical observation such that PA5 is composed of a high abundance of plagioclase. 


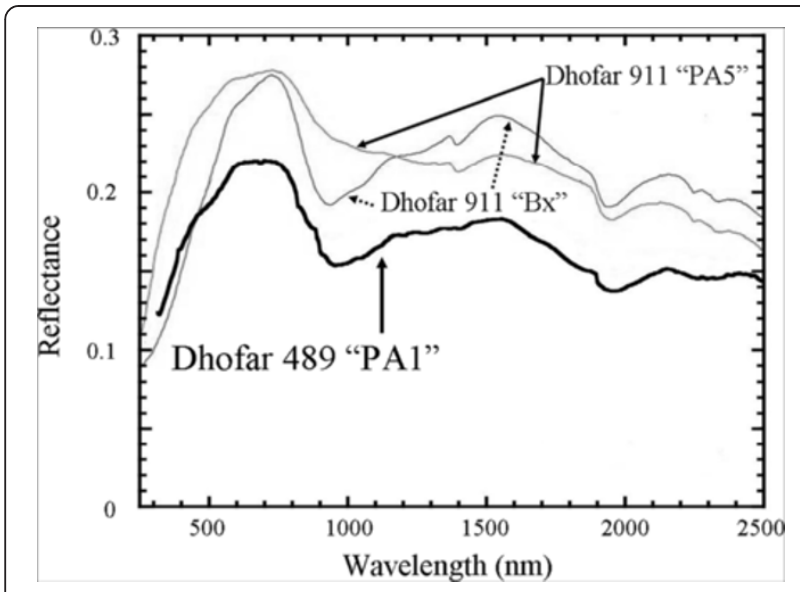

Figure 6 Reflectance spectrum of the PA1 clast in Dhofar 489. The spectrum of the PA1 is compared with the spectra of the PA5 embedded in Dhofar 911 and the Dhofar 911 breccia matrix (Bx) reported by Takeda et al. (2012).

Mineral chemistry and petrography of Apollo FAN, 60015 The textures of $60015,129(20 \times 7 \mathrm{~mm}$ in size; Figure 7a,b), show that 60015 is highly shocked, as explained by Dixon and Papike (1975) and Sclar et al. (1973). The average grain size of the pyroxene is approximately $0.1 \mathrm{~mm}$ in width. The entire PTS consists of clear fragments of plagioclase with uniform composition. Anorthite feldspar comprises more than $98 \%$ of this section on optical observation, which is similar to that previously reported in other sections of this sample (e.g., 113, 122, and 123 in Dixon and Papike 1975). Trace minerals include orthopyroxene and augite. No olivine is found in this section. Some plagioclase coexists with anhedral orthopyroxene (Figure 7a,b). Their textures are similar to those of PA1 in Dhofar 489, although some mafic minerals in 60015, 129, are larger than those in PA1.

\section{Plagioclase}

Plagioclase is the most dominant mineral (>98 area\%) in 60015,129 . The An values of euhedral to subhedral plagioclase are uniform $\left(\mathrm{An}_{96-97}\right)$ and are consistent with reported values of $\mathrm{An}_{95-98}$ (Sclar and Bauer 1974) and $\mathrm{An}_{\text {96.4-97.1 }}$ (Dixon and Papike 1975).

\section{Pyroxene}

Eighteen grains of orthopyroxene and three grains of augite are recognized in this section $(60015,129)$. The average composition of the orthopyroxenes is $\mathrm{Wo}_{2} \mathrm{En}_{64} \mathrm{Fs}_{34}$, and that of the augites is $\mathrm{Wo}_{45} \mathrm{En}_{41} \mathrm{Fs}_{14}$. The orthopyroxene compositions are within very limited ranges. The Mg\# 62 to 68 are consistent with that of orthopyroxene reported by Dixon and Papike $(63 ; 1975)$ and McGee (63 to 64; 1993). The augite compositions are also within very limited ranges. The Mg\# 73 to 77 are consistent with that of augite reported by Dixon and Papike $(74$ to $75 ; 1975)$ and McGee (76; 1993).

\section{Olivine}

Olivine is not observed in this section, nor is it found in other sections (e.g., Dixon and Papike 1975).

\section{Discussion}

Dhofar 489 has the lowest Th content and the highest Mg\# among the feldspathic lunar meteorites (Korotev et al. 2006; Takeda et al. 2006). Takeda et al. (2006) reported that the global map of Th and Fe distributions (e.g., Jolliff et al. 2000) suggests that Dhofar 489 may be derived from the farside of the Moon, owing to its very low Th and Fe contents. On the contrary, Korotev et al. (2006) suggested that its low concentrations of incompatible elements reflect depth and not necessarily distance from the Procellarum KREEP Terrane (PKT) (Jolliff et al. 2000) on the nearside. 'KREEP' materials are enriched in such elements as potassium (K), rare earth elements (REE), and phosphorus (P) (e.g., Taylor et al. 1991). The recent Kaguya data (Kobayashi et al. 2012; Ohtake et al. 2012) revealed that the central farside highland has a more primitive aspect owing to the lower Th content and higher Mg\#. Ohtake et al. (2009) reported the presence of pure anorthosite from observations by the multi-band imager (MI) data onboard Kaguya, in which the spatial resolution is 20-m VIS and
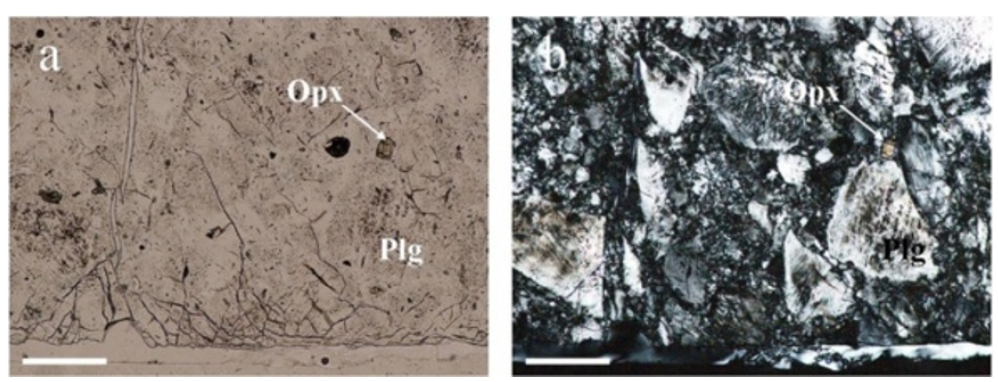

Figure 7 Photomicrographs of (a) plane-polarized and (b) cross-polarized views of polished thin section of 60015, 129. Plg, plagioclase; Opx, orthopyroxene. Scale bar is $0.3 \mathrm{~mm}$ in size. 
62-m NIR per pixel at a nominal altitude of $100 \mathrm{~km}$. As shown by Kobayashi et al. (2012), the spatial resolution of the Th map is $450 \mathrm{~km}$, which was degraded in order to improve the precision of the Th abundance, and the relative error is within several percentage points. The spatial resolution of the $\mathrm{Mg \#}$ map was $1^{\circ} \times 1^{\circ}(=30 \times$ $30 \mathrm{~km}$ in the equatorial area), and the relative error is within several percentage points (Ohtake et al. 2012). The spatial resolution of the remote sensing data could be originally larger than the representative scales of the chemical compositions of the lunar rock samples. In this case, the remote sensing data could provide the average composition of each footprint. Although the precision of remote sensing data is not quite as high as that of the sample data, the global trend of Th content and $\mathrm{Mg \#}$ over the Moon can be confirmed by the positional information because the variations of $\mathrm{Th}$ and $\mathrm{Mg \#}$ are significantly larger than their errors. With reference to their observation by the remote sensing data, we discuss the global anorthositic crust lithology by comparing the lunar highland samples.

\section{Mineralogy and petrology of the pure anorthosite clasts in feldspathic lunar meteorites, Dhofar $\mathbf{4 8 9}$ group}

In this section, the mineralogy and petrology of the five large pure anorthosite clasts embedded in Dhofar 489 and Dhofar 911 will be considered. Their textures are classified into three groups; most of the differences among textures may be associated with shock effects. Their shock textures by meteoritic impacts are commonly disturbed by networks of weathered products such as calcite produced at the hot desert in Oman (Korotev 2012).

Group I includes PA1 and PA5. Euhedral to subhedral plagioclase grains are coarse up to approximately $2 \mathrm{~mm}$ in this group. Significantly smaller mafic minerals exist in the grain boundaries between igneous plagioclase grains with albite twinning textures. BSE images of mafic minerals in PA1 are shown in Figure 8. Angular olivines are observed between large igneous plagioclase grains. These angular textures of mafic minerals differ from the generally rounded mafic minerals of granulite. We can recognize an igneous crystalline texture with albite twinning within each original crystal (Figure 2b). Therefore, we may conclude that PA1 is part of a coarse-grained, igneous anorthosite. If shock-produced twin lamellae were annealed after metamorphic events to produce granulites, such lamellae texture would have disappeared (Takeda et al. 2006). Large euhedral to subhedral plagioclase crystals of PA1 enclosing the small angular mafic minerals may suggest that an early plagioclase crystallized at a high temperature in the magma and accumulated; at that phase, the plagioclase grains trapped small amounts of liquid in the grain boundaries. During the temperature decrease, small mafic mineral grains were crystallized from the trapped liquids. However, an alternative hypothesis may be considered such that these clasts were brecciated and recrystallized from fragments of large single crystals of plagioclase by deformation and shock events.

Group II includes PA2 and PA4, which are composed of plagioclase crystals of varying sizes (Figure 3 ) that are apparently finer than those of PA1. These brecciated anorthosites may have experienced shock events and were then metamorphosed from coarse-grained igneous anorthosite such as PA1 or larger single crystals of plagioclase. The compositions of minerals in each clast are homogeneous and include plagioclase $\left(\mathrm{An}_{94-97}\right)$ and traces of low-Ca pyroxene (Mg\# 71 to 72$)$ in PA2 and plagioclase $\left(\mathrm{An}_{94-96}\right)$, olivine $\left(\mathrm{Fo}_{64-68}\right)$, and low-Ca pyroxene (Mg\# 70) in PA4.

Group III includes PA3, which is a highly shocked brecciated anorthosite consisting of fine-grained plagioclase $\left(\mathrm{An}_{95-97}\right)$ similar to those in group II. The chemical compositions of the mafic minerals in the $\mathrm{d} 4$ clast are heterogeneous (Mg\# 30 to 70) and include olivine $\left(\mathrm{Fo}_{57}\right)$, low-Ca pyroxene (Mg\# 69 to 71$)$, and augite ( $\mathrm{Mg} \# 29,72)$. Although the texture is similar to that of group II, this clast could be a mechanically mixed breccia of differentiated pure anorthosite lithologies, as indicated by the large compositional variation in the mafic minerals.
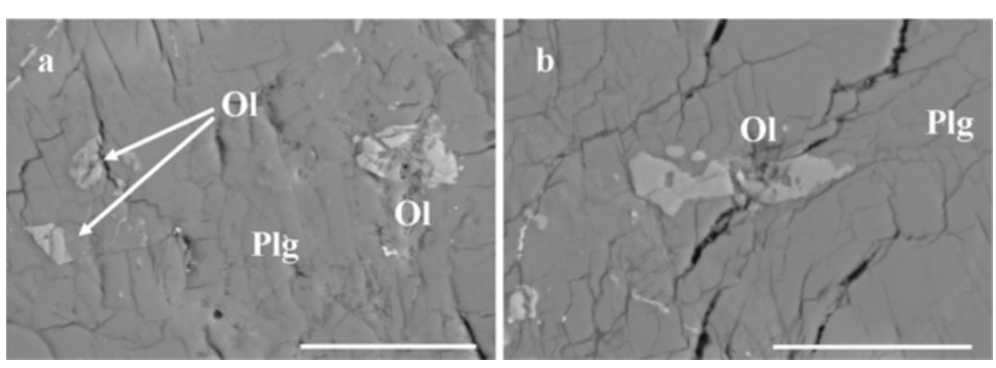

Figure 8 Backscattered electron (BSE) images of mafic minerals in PA1 (a, b). Plg, plagioclase; Ol, olivine. Scale bar is $0.05 \mathrm{~mm}$ in size. (a) Shows enlarged BSE image of Figure 2b. 
Plagioclase compositions in the four pure anorthosite clasts in Dhofar 489 are within a very narrow compositional range $\left(\mathrm{An}_{94-97}\right)$. The mafic mineral compositions in PA1 ( $\mathrm{Fo}_{61-63}$ of olivine; Mg\# 60 to 66 of Opx), PA2 (Mg\# 71 to 72 of low-Ca pyroxene), and PA4 ( $\mathrm{Fo}_{64-68}$ of olivine; $\mathrm{Mg \#} 70$ of low-Ca pyroxene) are uniform in each clast. Previous research of Dhofar 489 (Takeda et al. 2006) indicated that the olivine $\left(\mathrm{Fo}_{78}\right)$ in $\mathrm{AN} 1$ is more magnesian than the mafic minerals in other pure anorthosites in Dhofar 489 (PA1 to PA4). The plagioclase compositions in PA5 in Dhofar 911 are within a very narrow range $\left(\mathrm{An}_{95-96}\right)$ similar to the pure anorthosites in Dhofar 489 (PA1 to PA4). Olivine compositions in PA5 $\left(\mathrm{Fo}_{75-85}\right)$ are more magnesian than the mafic minerals in the Dhofar 489 pure anorthosites. These pure anorthosite clasts in the Dhofar 489 group show chemical variations in the $\mathrm{Mg} \#$ of mafic minerals.

The bulk chemical composition of PA1 (d2) was reported in previous works (Karouji et al. 2004; Takeda et al. 2006). The texture of the PA1 is partly disturbed by networks of weathered products (e.g., calcite) at the hot desert in Oman (Figure 2c). Therefore, the bulk composition of PA1 (Takeda et al. 2006) may involve terrestrial weathered products (Korotev 2012). Siderophile element abundances in PA1 are Co at $1.6 \mathrm{ppm}, \mathrm{Ni}$ at $<18 \mathrm{ppm}$, and Ir at $<3$ ppb. The bulk Ni content in the PA1 clast is below the detection limit and thus gives a low bulk Ni/Co ratio of $<11$ (Karouji et al. 2004; Takeda et al. 2006). These data support the theory that this clast is a pristine rock fragment scarcely affected by meteoritic contamination.

\section{Mineralogy and petrology of Apollo FAN 60015 as compared with other Apollo FAN samples}

Anorthosites of the Apollo samples, referred to as FAN owing to their ferroan compositions, were produced in the more evolved magma ocean (e.g., Warren 1985, 1990). According to the modal and mineralogical data of FAN, this suite could be divided into several subgroups including anorthositic ferroan (AF), mafic magnesian (MM), anorthositic sodic (AS), and mafic ferroan (MF), as explained by James et al. $(1989,2002)$ and Floss et al. (1998). a

\section{5}

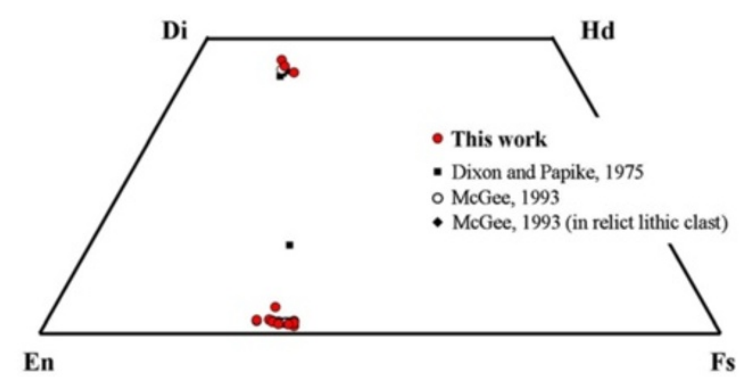

C
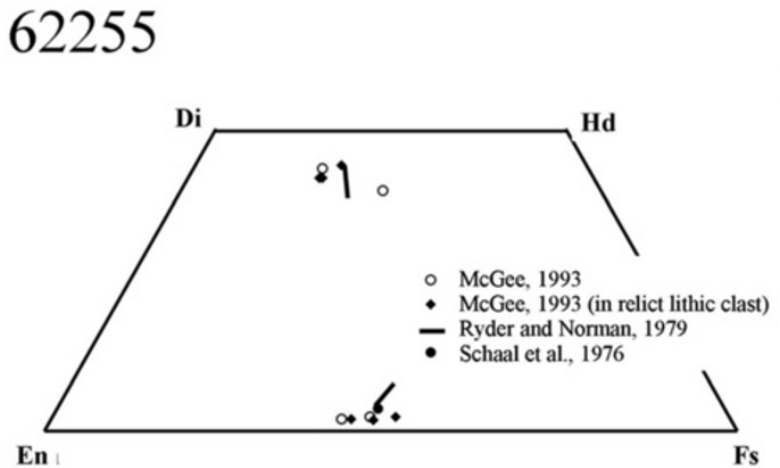

b

\section{5}

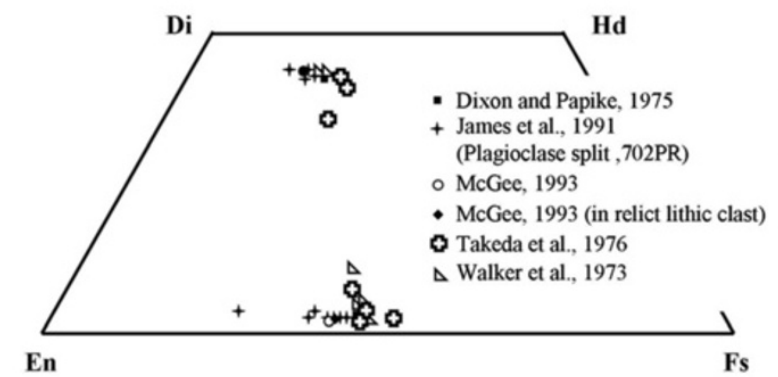

$\mathrm{d}$

\section{5}

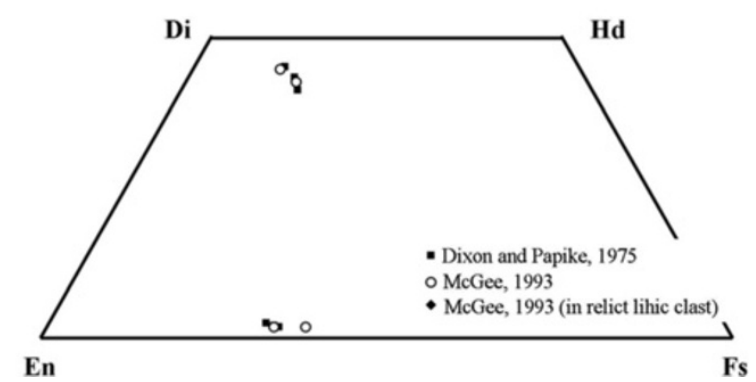

Figure 9 Pyroxene compositions in Apollo ferroan anorthosites: (a) 60015, (b) 60025, (c) 62255, and (d) 65315. Data of 60015 pyroxenes are from this work (red circles) in addition to Dixon and Papike (1975) and McGee (1993). Data of 60025 pyroxenes are derived from Dixon and Papike (1975), James et al. (1991), McGee (1993), Takeda et al. (1976), and Walker et al. (1973). Pyroxene data in the anorthosite in 62255 are derived from McGee (1993), Ryder and Norman (1979), and Schaal et al. (1976). Data of 65315 pyroxenes are derived from Dixon and Papike (1975) and McGee (1993). 
Pyroxenes are highly important minerals as recorders of the evolutionary history of rocks in the magma ocean. Figure 9a summarizes the pyroxene compositions of 60015 including our data and further the results with those of other FAN samples including 60025, 62255, and 65315 (Figure 9b,c,d), which are recognized as pristine rocks (e.g., Warren 1993). The entire mass of 60015 is $5.57 \mathrm{~kg}$, which makes it the largest rock among Apollo FAN samples. The orthopyroxene compositions of 60015 are homogeneous $\left(\mathrm{En}_{62}\right.$ to $\left.\mathrm{En}_{67}\right)$ in comparison with those of other FAN samples. Furthermore, 60015 is homogeneous in the modal abundance of plagioclase (>98\%). Although 60015 can be categorized as AF on the criteria of James et al. (1989), our mineralogical data and the results of previous works (e.g., Dixon and Papike 1975) further suggest that 60015 is a pristine pure anorthosite of the FAN type owing to the homogeneity of its mineral compositions and purity. FAN sample 60025 is heterogeneous in modal abundance of plagioclase among some sections (70\% to 99\%: Dixon and Papike 1975; James et al. 1991; Warren and Wasson 1977), containing AF and MM anorthosites (e.g., Floss et al. 1998). Large compositional variations of orthopyroxenes $\left(\mathrm{En}_{48}\right.$ to $\left.\mathrm{En}_{70}\right)$ in the different portions of 60025 (Figure 9b) may be attributed to a mixture of different lithology types (e.g., Floss et al. 1998; James et al. 1991; Ryder 1982; Takeda et al. 1976).

\section{Implication for lunar anorthositic crust model on the study of lunar anorthosite samples}

The original LMO model on the basis of the Apollo samples assumed that flotation of plagioclase was produced by one-dimensional convection on the magma surface. However, the gamma-ray spectrometer and spectral profiler on Kaguya revealed compositional dichotomous distributions in the highlands of Th abundances (Kobayashi et al. 2012) and Mg\# (Ohtake et al. 2012) in which indicated the central farside highland showed the lowest Th abundance and highest Mg\# among feldspathic highland regions.

Studies of Apollo/Luna samples and lunar meteorites have revealed that nearly all feldspathic highland samples are polymict rocks heavily brecciated by numerous impacts and metamorphosed by shock heating (e.g., Cahill et al. 2004; Cohen et al. 2005; Joy et al. 2010; Korotev 2005; Lindstrom and Lindstrom 1986; Nagaoka et al. 2013; Warren et al. 2005; Yamaguchi et al. 2010).

The samples of the Dhofar 489 group are crystalline matrix anorthositic breccias composed of diverse mixtures of lithic or glassy clasts including impact-melt breccias and granulitic breccias (Takeda et al. 2006, 2007, 2008; Treiman et al. 2010). Although magnesian anorthosites (MA1, MA2; Takeda et al. 2006) and the magnesian anorthosite with the granulitic breccia texture (Figure 5) are less metamorphosed than the lunar magnesian granulitic breccias in the Dhofar 489 group (e.g., Takeda et al. 2006, 2007, 2008; Treiman et al. 2010), their textures including aggregates of olivines with rounded shapes suggest that they may have been thermally metamorphosed. Such magnesian clasts found in feldspathic lunar meteorites are implied to be different from Mg-suite rocks returned from the central nearside by Apollo missions due to a lack of incompatible elements such as REEs (e.g., Takeda et al. 2006; Treiman et al. 2010). The origin of these magnesian rocks without KREEP signatures is assumed to be not a direct formation from a magma ocean; rather, they could be products of more complex crustal formation processes (Gross et al. 2014). Furthermore, these magnesian clasts are commonly brecciated by numerous impacts and were thermally metamorphosed by shock heating; thus, they could have experienced complex metamorphic processes (Takeda et al. 2012).

The present study has detected several pure anorthosite clasts in the Dhofar 489 group. The pure anorthosites PA1 and PA5 may have preserved coarse-grained textures; other pure anorthosites could have been metamorphosed from coarse-grained pure anorthosite or large single crystals of plagioclase by deformation or recrystallization. Figure 10 plots the mineral compositions of the pure anorthosites in Dhofar 489 (PA1, PA3, PA4, and AN1), Dhofar 911 (PA5), and the Apollo sample (60015). The Mg\# of each pure anorthosite in the Dhofar 489 group (Figure 10a) is relatively uniform within several millimeters except for PA3, despite the fact that large variations of $\mathrm{Mg \#}$ were found among the pure anorthosites. The lunar anorthosite, 60015, could be a monomict mixture of pure anorthosites at the same stage in the nearside magma ocean because of its narrow compositional variation of mafic minerals (Figure 10b). Studies of anorthosite samples suggest that these pure anorthosites were possibly excavated on the lunar surface from a global pure anorthosite layer (Ohtake et al. 2009; Yamamoto et al. 2012) existing below an uppermost mafic-rich mixed layer (e.g., Hawke et al. 2003). Parmentier and Liang (2010) calculated the trapped melt fraction due to freezing at the top of the magma ocean based on the various grain sizes and a liquid viscosity of $10 \mathrm{~Pa}$. According to this estimation, a trapped melt fraction of less than $2 \%$, as indicated by SELENE measurements, is possible if the grain size is sufficiently coarse, such as a few millimeters in size. This fraction corresponds to the mafic mineral content of the anorthosite. The model calculation by Piskorz and Stevenson (2014) indicates that the plagioclase crystals had already formed and that the interstitial mafic minerals were still liquid, thereby resulting in a minimum trapped interstitial melt fraction of $2 \%$. Their calculation results associated with 

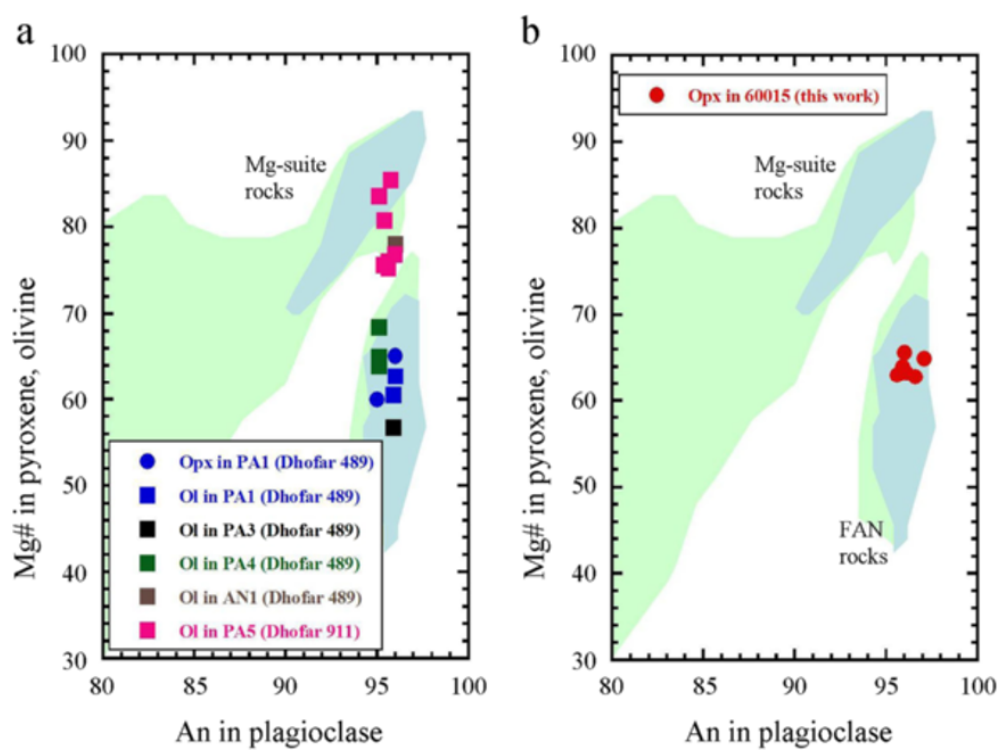

Figure 10 Mineral chemistry of the pure anorthosite clasts in Dhofar 489, Dhofar 911, and FAN 60015. Mineral compositions of (a) the pure anorthosite clasts in Dhofar 489 (PA1, PA3, PA4, and AN1), Dhofar 911 (PA5), and (b) 60015 (this work) are plotted in the plagioclase An values vs. Mg\# (=molar $100 \times \mathrm{Mg} /(\mathrm{Mg}+\mathrm{Fe})$ ) of coexisting olivine $(\mathrm{Ol})$ and orthopyroxene (Opx). The classical differentiation trends are ferroan anorthosite (FAN)-suite and Mg-suite rocks (e.g., Warner et al. 1976; Warren and Wasson 1977). The areas were taken from Yamaguchi et al. (2010). The areas in light blue represent confidence $\geqq 7$, and those in light green represent confidence $\leqq 6$ (Warren 1993).

a huge magma system support the presence of pure anorthosite as lunar crust lithology.

Ohtake et al. (2012) presented an asymmetric crustal growth model for interpreting the dichotomy of $\mathrm{Mg \#}$ distribution with a higher $\mathrm{Mg} \#$ in the farside than that in the nearside. The model (Ohtake et al. 2012) uses a surface convectional force from the nearside to the farside generated by a higher temperature on the nearside caused by thermal shielding of the Earth on a tilted convection model (Loper and Werner 2002). This forcetransported plagioclase crystallized at the first stage of crustal formation in the farside. Moreover, a high Mg\# anorthosite 'rockburg' developed in the farside, and the ferroan crust crystallized from the more evolved magma formed in the nearside (Ohtake et al. 2012). If large Mg\# variations of mafic minerals among the pure anorthosites could reflect the global trend of the anorthositic crust as observed by the remote sensing data, the $\mathrm{Mg} \#$ variations of mafic minerals among the pure anorthosites could be explained by the different timing of crystallization sequence during the asymmetric crustal growth crystallization (Ohtake et al. 2012), which resulted in either lateral (regional) or vertical (depth) heterogeneity of the putative massive layer of pure anorthosite (Ohtake et al. 2009; Yamamoto et al. 2012).

If the variations in $\mathrm{Mg \#}$ could be derived from relatively local variations over small distances inside the same cumulate rock, merely a sequence of compositional changes by crystallization of a huge magma system could not explain such local variations. If so, pure anorthosite may have undergone fractional crystallization in the cumulate pile, which resulted in large variations of $\mathrm{Mg \#}$ (from approximately 80 to approximately 60) over small distances. A special mechanism to explain such large variations within local regions is required, although a specific process explaining the variations on the Moon has not been determined thus far. Anorthosites with high abundances of plagioclase ( $>95 \%)$ on the Earth are produced by deformation (Lafrance et al. 1996). If the lunar pure anorthosite could be produced by deformation or recrystallization, such Mg\# variation could occur locally by such processes. Relatively mafic-rich anorthosite could be derived from the remaining liquid, as discussed by Ohtake et al. (2009). However, although we could confirm a global trend of Mg\# in the lunar anorthositic crust (Ohtake et al. 2012), it would be difficult to explain such a global trend merely by local variations of $\mathrm{Mg \#}$ caused by recrystallization and deformation processes.

\section{Conclusions}

In this paper, we performed mineralogical and petrologic investigations on lunar meteorites Dhofar 489 and Dhofar 911 and the Apollo returned FAN sample 60015. Several pure anorthosite clasts have been found in the Dhofar samples, and 60015 is an anorthosite with high abundance of plagioclase and uniform composition in comparison with other FAN samples. These anorthosite samples are thought to be identified as pure anorthosite 
rocks composed of high abundances of igneous plagioclase ( $>98 \%$ plagioclase) or metamorphosed anorthosite from such pure anorthosites. The recent remote observation by the Kaguya (Ohtake et al. 2009; Yamamoto et al. 2012) showed that PAN ( $>98 \%$ plagioclase) spots are widely distributed over the Moon. These samples may be able to indicate the ground truth of PAN.

The combination of our petrologic and mineralogical studies for the pure anorthosite samples and Kaguya remote sensing results of PAN could have a profound implication for the global existence of PAN in feldspathic rocks. Furthermore, these pure anorthosites of the Dhofar 489 group show large chemical variations in Mg\# from nearly 60 to more than 80 of each coexisting mafic mineral. The variations of Mg\# observed among the pure anorthosite samples imply that those pure anorthosites were not formed from simple flotation of plagioclase but instead underwent a more complex formation process. The presence of pure anorthosite samples necessitates reconsideration of the origin and processes of crustal formation.

\section{Abbreviations}

BSE: backscattered electron; Bx: breccia matrix; CRE: cosmic-ray exposure; EPMA: electron probe micro-analyzer; FAN: ferroan anorthosite; ICPMS: inductively coupled plasma mass spectrometry; LMO: lunar magma ocean; MA clast: magnesian anorthosite clast; MI: multi-band imager; PA clast: pure anorthosite clast; PAN: purest anorthosite; PGA: neutron-induced prompt gamma-ray analysis; PTS: polished thin section; SEM: scanning electron microscope; SP: spectral profiler.

\section{Competing interests}

The authors declared that they have no competing interests.

\section{Authors' contributions}

$\mathrm{HN}$ and HT designed this study and performed the mineralogical and petrologic studies of the samples. YK participated in the design of the study and provided the bulk chemical data of Dhofar 489. Reflectance spectroscopy of Dhofar 489 PA1 was performed by MO and HN. The mineralogical study of Apollo 60015 was performed by MO, HN, and HT. AY and SY supported sample preparations of Dhofar 489. This work was encouraged by $\mathrm{NH}$. HN, HT, YK, and $\mathrm{MO}$ contributed to the data interpretation and the paper writing. All of the authors discussed the results. All authors read and approved the final manuscript.

\section{Acknowledgements}

We appreciate professor emeritus Manabu Kato of JAXA/ISAS for providing us with the meteorite sample Dhofar 911. The study of the PTS of 60015 $(60015,129)$ was enabled by NASA/JSC (PI: Makiko Ohtake). Mineralogical analyses were supported by the National Institute of Polar Research, Tokyo, and the cooperative program (2012, No. 108; 2013, No. 111; H. Takeda) of the Atmosphere and Ocean Research Institute at the University of Tokyo. This work was in part supported by Research Fellowships of the Japan Society for the Promotion of Science for Young Scientists, and a Waseda University Grant for Special Research Projects (Project No. 2013A-900). We greatly appreciate Yasuo Ogawa, Hauke Hussmann, and two anonymous reviewers for their helpful comments and suggestions for improving this manuscript.

\section{Author details}

${ }^{1}$ Research Institute for Science and Engineering, Waseda University, Shinjuku, Tokyo 169-8555, Japan. ${ }^{2}$ Schools of Advanced Science and Engineering, Waseda University, Shinjuku, Tokyo 169-8555, Japan. ${ }^{3}$ Department of Earth \& Planetary Science, University of Tokyo, Hongo, Tokyo 113-0033, Japan. ${ }^{4}$ Institute of Space and Astronautical Science (ISAS), Japan Aerospace Exploration Agency (JAXA), Sagamihara, Kanagawa 252-5210, Japan. ${ }^{5}$ Planetary Science Department, Japan Aerospace Exploration Agency (JAXA),
Sagamihara, Kanagawa 252-5210, Japan. ${ }^{6}$ National Institute of Polar Research (NIPR), Tachikawa, Tokyo 190-8518, Japan. Department of Polar Science, School of Multidisciplinary Science, Graduate University for Advanced Studies, Tokyo 173-8518, Japan. ${ }^{8}$ National Museum of Nature and Science (NMNS), Tsukuba, Ibaraki 305-0005, Japan.

Received: 10 April 2014 Accepted: 2 September 2014 Published: 10 September 2014

\section{References}

Binder AB (1998) Lunar prospector: overview. Science 281:1475-1476

Cahill JT, Floss C, Anand M, Taylor LA, Nazarov MA, Cohen BA (2004) Petrogenesis of lunar highlands meteorites: Dhofar 025, Dhofar 081; Dar al Gani 262, and Dar al Gani 400. Meteorit Planet Sci 39:503-530

Cohen BA, Swindle TD, Kring DA (2005) Geochemistry and 40Ar-39Ar geochronology of impact-melt clasts in feldspathic lunar meteorites: Implications for lunar bombardment history. Meteorit Planet Sci 40:755-777

Dixon JR, Papike JJ (1975) Petrology of anorthosites from the Descartes region of the moon: Apollo 16. In: Lunar Science Conference, 6th edn. Proc. 6th Lunar Sci Conf, Houston, TX, pp 263-291

Floss C, James OB, McGee JJ, Crozaz G (1998) Lunar ferroan anorthosite petrogenesis: clues from trace element distributions in FAN subgroups. Geochim Cosmochim Acta 62:1255-1283

Gross J, Treiman AH, Mercer CN (2014) Lunar feldspathic meteorites: constraints on the geology of the lunar highlands, and the origin of the lunar crust. Earth Planet Sci Lett 388:318-328

Hawke BR, Peterson CA, Blewett DT, Bussey DBJ, Lucey PG, Taylor GJ, Spudis PD (2003) Distribution and modes of occurrence of lunar anorthosite. J Geophys Res 108:E6, 10.1029/2002JE001890

James OB, Lindstrom MM, Flohr MK (1989) Ferroan anorthosite from lunar breccia 64435: implications for the origin and history of lunar ferroan anorthosites. In: Lunar and Planetary Science Conference, 19th edn. Proc. 19th Lunar Planet Sci Conf, Houston, TX, pp 219-243

James OB, Lindstrom MM, McGee JJ (1991) Lunar ferroan anorthosite 60025 petrology and chemistry of mafic lithologies. In: Lunar and Planetary Science Conference, 21st edn. Proc. 21st Lunar Planet Sci Conf, Houston, TX, pp 63-87

James OB, Floss C, McGee JJ (2002) Rare earth element variations resulting from inversion of pigeonite and subsolidus reequilibration in lunar ferroan anorthosites. Geochim Cosmochim Acta 65:1269-1284

Jolliff BL, Gillis JJ, Haskin LA, Korotev RL, Wieczorek MA (2000) Major lunar crustal terranes: surface expressions and crust-mantle origins. J Geophys Res 105:4197-4216

Joy KH, Crawford IA, Russell SS, Kearsley AT (2010) Lunar meteorite regolith breccias: an in situ study of impact melt composition using LA-ICP-MS and implications for the composition of the lunar crust. Meteorit Planet Sci 45:917-946

Karouji Y, Ebihara M, Yamaguchi A (2004) Chemical characteristics of lunar meteorites, Yamato 86032 and Dhofar 489. In: The Twenty-eighth Symposium on Antarctic Meteorites. Antarctic Meteorites XXVIII, Tokyo, pp 29-30

Kato M, Sasaki S, Takizawa Y, Kaguya Project T (2010) The Kaguya mission overview. Space Sci Rev 154:3-19

Kobayashi S, Karouji Y, Morota T, Takeda H, Hasebe N, Hareyama M, Kobayashi M, Shibamura E, Yamashita N, D'Uston C, Gasnault O, Forni O, Reedy RC, Kim Y, Ishihara KJ (2012) Lunar farside Th distribution measured by Kaguya gamma-ray spectrometer. Earth Planet Sci Lett 337-338:10-16

Korotev RL (2005) Lunar geochemistry as told by lunar meteorites. Chem Der Erde 65:297-346

Korotev RL (2012) Lunar meteorites from Oman. Meteorit Planet Sci 47:1365-1402

Korotev RL, Zeigler RA, Jolliff BL (2006) Feldspathic lunar meteorites Pecora Escarpment 02007 and Dhofar 489: contamination of the surface of the lunar highlands by post-basin impacts. Geochim Cosmochim Acta 70:5935-5956

Korotev RL, Jolliff BL, Zeigler RA (2010) On the origin of the Moon's feldspathic highlands, pure anorthosite, and the feldspathic lunar meteorites. In: Lunar and Planetary Science Conference, 41st edn. Lunar Planet Sci Conf XXXXI, the Woodlands, TX, Abstract \#1440

Lafrance B, John BE, Scoates JS (1996) Syn-emplacement recrystallization and deformation microstructures in the Poe Mountain anorthosite, Wyoming. Contrib Mineral Petrol 122:431-440 
Lindstrom MM, Lindstrom DJ (1986) Lunar granulites and their precursor anorthositic norites of the early lunar crust. In Lunar and Planetary Science Conference, 16th, Houston, TX, 11-15 March 1985. Proc. 16th Lunar Planet Sci Conf. J Geophys Res 91:D263-D276

Loper DE, Werner CL (2002) On lunar asymmetries 1. Tilted convection and crustal asymmetry. J Geophys Res 107:5046

McGee JJ (1993) Lunar ferroan anorthosites: mineralogy, compositional variations, and petrogenesis. J Geophys Res 98:9089-9105

Nagaoka H, Takeda H, Karouji Y, Ohtake M, Yamaguchi A, Yoneda S, Hasebe N (2011) Mineral chemistry and reflectance spectra for the anorthosite clast in lunar meteorite Dhofar 489 with reference to lunar farside crust. In: The Thirty-fourth Symposium on Antarctic Meteorites. Antarctic Meteorites XXXIV, Tokyo, pp 56-57

Nagaoka H, Takeda H, Karouji Y, Ohtake M, Yamaguchi A, Yoneda S, Hasebe N (2012) Comparisons of mineralogy of pure anorthosite in lunar meteorites, Dhofar 489 group and pure anorthosite observed by Kaguya. In 75th Annual Meeting of the Meteoritical Society, Cairns, 12-17 August 2012. Meteorit Planet Sci 47(Supplement s1):A35-A436, Abstract No.5197

Nagaoka H, Karouji Y, Arai T, Ebihara M, Hasebe N (2013) Geochemistry and mineralogy of a feldspathic lunar meteorite (regolith breccia), Northwest Africa 2200. Polar Sci 7:241-259

Nishiizumi K, Caffee MW (2006) Constraining the number of lunar and Martian meteorite falls. In 69th Annual Meeting of the Meteoritical Society, Zurich, 6-11 August 2006. Meteorit Planet Sci 41 (Supplement): A13-A199, Abstract No.5368

Nozette S, Rustan P, Pleasance LP, Horan DM, Regeon P, Shoemaker EM, Spudis PD, Acton CH, Baker DN, Blamont JE, Buratti BJ, Corson MP, Davies ME, Duxbury TC, Eliason EM, Jakosky BM, Kordas JF, Lewis IT, Lichtenberg CL, Lucey PG, Malaret E, Massie MA, Resnick JH, Rollins CJ, Park HS, McEwen AS, Priest RE, Pieters CM, Reisse RA, Robinson MS et al (1994) The clementine mission to the moon-scientific overview. Science 266:1835-1839

Ohtake M, Matsunaga T, Haruyama J, Yokota Y, Morota T, Honda C, Ogawa Y, Torii M, Miyamoto H, Arai T, Hirata N, Iwasaki A, Nakamura R, Hiroi T, Sugihara T, Takeda H, Otake H, Pieters CM, Saiki K, Kitazato K, Abe M, Asada N, Demura H, Yamaguchi Y, Sasaki S, Kodama S, Terazono J, Shirao M, Yamaji A, Minami $S$ et al (2009) The global distribution of pure anorthosite on the Moon. Nature 461:236-240

Ohtake M, Takeda H, Matsunaga T, Yokota Y, Haruyama J, Morota T, Yamamoto S, Ogawa Y, Hiroi T, Karouji Y, Saiki K, Lucey PG (2012) Asymmetric crustal growth on the Moon indicated by primitive farside highland materials. Nat Geosci 5:384-388

Parmentier EM, Liang Y (2010) Formation of pure anorthosite during lunar magma ocean solidification: implications for the melt-solid segregation process. In: Lunar and Planetary Science Conference, 41st edn. Lunar Planet Sci Conf XXXXI, the Woodlands, TX, Abstract \#1824

Piskorz D, Stevenson DJ (2014) The formation of pure anorthosite on the Moon. Icarus 239:238-243

Prinz M, Keil K (1977) Mineralogy, petrology and chemistry of ANT-suite rocks from the lunar highlands. Phys Chem Earth 10:215-237

Ryder G (1982) Lunar anorthosite 60025, the petrogenesis of lunar anorthosites and the composition of the Moon. Geochim Cosmochim Acta 46:1591-1601

Ryder G, Norman MD (1979) Catalog of pristine non-mare materials Part 2. Anorthosites. Revised. Curators Office JSC \#14603., pp 40-42

Schaal RB, Horz F, Gibbons RV (1976) Shock metamorphic effects in lunar microcraters. In: Lunar Science Conference, 7th edn. Proc. 7th Lunar Sci Conf, Houston, TX, pp 1039-1054

Sclar CB, Bauer JF (1974) Shock-induced melting in anorthositic rock 60015 and a fragment of anorthositic breccia from the 'picking pot' (70052). In: Lunar Science Conference, 5th edn. Proc. 5th Lunar Sci Conf. Geochim. Cosmochim. Acta 1, Supplement 5, Houston, TX, pp 319-336

Sclar CB, Bauer JF, Pickart SJ, Alperin HA (1973) Shock effects in experimentally shocked terrestrial ilmenite, lunar ilmenite of rock fragments in 1-10 mm fines $(10085,19)$, and lunar rock 60015,127. In: Lunar Science Conference, 4th edn. Proc. 4th Lunar Sci Conf, Geochim. Cosmochim. Acta 1, Supplement 4, Houston, TX, pp 841-859

Takeda H, Miyamoto M, Ishii T, Reid AM (1976) Characterization of crust formation on a parent body of achondrites and the Moon by pyroxene crystallography and chemistry. In: Lunar Science Conference, 7th edn. Proc. 7th Lunar Sci Conf, Houston, TX, pp 3535-3548
Takeda H, Yamaguchi A, Bogard DD, Karouji Y, Ebihara M, Ohtake M, Saiki K, Arai $T$ (2006) Magnesian anorthosites and a deep crustal rock from the farside crust of the moon. Earth Planet Sci Lett 247:171-184

Takeda H, Arai T, Yamaguchi A, Otuki M, Ishii T (2007) Mineralogy of Dhofar 309, 489 and Yamato-86032 and varieties of lithologies of the lunar farside crust. In: Lunar and Planetary Science Conference, 38th edn. Lunar Planet Sci Conf XXXVIII, League city, TX, Abstract \#1607

Takeda H, Arai T, Yamaguchi A, Otuki M, Ohtake M (2008) Granulitic lithologies in Dhofar 307 lunar meteorite and magnesian, Th-poor terrane of the northern farside crust. In: Lunar and Planetary Science Conference, 39th edn. Lunar Planet Sci Conf XXXIX, League city, TX, Abstract \#1574

Takeda H, Nagaoka H, Ohtake M, Kobayashi S, Yamaguchi A, Morota T, Karouji Y, Haruyama J, Katou M, Hiroi T, Nyquist LE (2012) Comparisons of mineralogy of lunar meteorites possibly from the farside and the Kaguya remote sensing data to reconstruct the earliest anorthositic crust of the Moon. In: Lunar and Planetary Science Conference, 43rd edn. Lunar Planet Sci Conf XXXXIII, the Woodlands, TX, Abstract \#1379

Taylor GJ, Warren PH, Ryder G, Delano J, Pieters C, Lofgren G (1991) Lunar rocks. In: Heiken GH, Vaniman DT, French BM (eds) Lunar Sourcebook. Cambridge Univ. Press, New York, pp 183-284

Treiman AH, Maloy AK, Shearer CK Jr, Gross J (2010) Magnesian anorthositic granulites in lunar meteorites Allan Hills A81005 and Dhofar 309: geochemistry and global significance. Meteorit Planet Sci 45:163-180

Walker D, Longhi J, Grove TL, Stolper E, Hays JF (1973) Experimental petrology and origin of rocks from the Descartes Highlands. In: Lunar Science Conference, 4th edn. Proc. 4th Lunar Sci Conf, Houston, TX, pp 1013-1032

Warner JL, Simonds CH, Phinney WC (1976) Genetic distinction between anorthosites and Mg-rich plutonic rocks: new data from 76255. In: Lunar Science Conference, 7th edn. Lunar Sci Conf VIl:Abstract, Houston, TX, pp 915-917

Warren PH (1985) The magma ocean concept and lunar evolution. Ann Rev Earth Planet Sci 13:201-240

Warren PH (1990) Lunar anorthosites and the magma ocean hypothesis: importance of FeO enrichment in the parent magma. Am Mineral 75:46-58

Warren PH (1993) A concise compilation of petrologic information on possibly pristine nonmare Moon rocks. Am Mineral 78:360-376

Warren PH, Kallemeyn GW (1991) Geochemical investigations of five lunar meteorites: implications for the composition, origin and evolution of the lunar crust. Proc. NIPR Symp Antarct Meteorites 4:91-117

Warren PH, Wasson JT (1977) Pristine nonmare rocks and the nature of the lunar crust. In: Lunar Science Conference, 8th edn. Proc. 8th Lunar Sci Conf, Houston, TX, pp 2215-2235

Warren PH, Ulff-Møller F, Kallemeyn GW (2005) 'New' lunar meteorites: impact melt and regolith breccias and large-scale heterogeneities of the upper lunar crust. Meteorit Planet Sci 40:989-1014

Wieczorek MA, Jolliff BL, Khan A, Pritchard ME, Weiss BP, Williams JG, Hood LL, Righter K, Neal CR, Shearer CK, McCallum IS, Tompkins S, Hawke BR, Peterson C, Gillis JJ, Bussey B (2006) The constitution and structure of the lunar interior. In: Jolliff BL, Wieczorek MA, Shearer CK, Neal CR (eds) New views of the moon, reviews in mineralogy \& geochemistry, vol 60. Mineralogical Society America Press, Virginia, pp 221-364

Yamaguchi A, Karouji Y, Takeda H, Nyquist L, Bogard D, Ebihara M, Shih C-Y, Reese Y, Garrison D, Park J, McKay G (2010) The variety of lithologies in the Yamato-86032 lunar meteorite: implications for formation processes of the lunar crust. Geochim Cosmochim Acta 74:4507-4530

Yamamoto S, Nakamura R, Matsunaga T, Ogawa Y, Ishihara Y, Morota T, Hirata N, Ohtake M, Hiroi T, Yokota Y, Haruyama J (2012) Massive layer of pure anorthosite on the Moon. Geophys Res Lett 39, L13201

doi:10.1186/1880-5981-66-115

Cite this article as: Nagaoka et al:: Implications for the origins of pure anorthosites found in the feldspathic lunar meteorites, Dhofar 489 group. Earth, Planets and Space 2014 66:115. 